Methods Cross-sectional, random study of 40 patients in a private practice, submitted to the SF-36 questionnaire and to a Vitamin D serum dosage.

Results Average age is 52 years ( \pm 8.58 ); $95 \%$ of participants have a college degree. The great majority displays skin pigmentation between levels II (40\%) and II/III (55\%), according to the Fitzgerald Skin Types, and $75 \%$ of them relate scarce sun exposure. The average dosage of Vitamin D is $20.05 \mathrm{ng} / \mathrm{ml}( \pm 7.96)$, and insufficient levels $(<30 \mathrm{ng} / \mathrm{ml})$ were detected in $90 \%$ of the patients. However, the analysis of the SF-36 revealed positive perception of both physical and mental health, with more than $70 \%$ of favourable answers to the items analysed, including degree of pain, vitality, physical aspects, functional capacity, social and emotional aspects, and mental health. In spite of that, $92.5 \%$ declare little leisure time.

Conclusions The reduction of Vitamin D was positively related with low sun exposure, not associated with skin colour or quality of life. Based on these results, the high incidence of hypovitaminosis D in women from a tropical country leads us to suggest the importance of a routine dosage of Vitamin D.

\section{SP6-50 OCCUPATIONAL PESTICIDE EXPOSURE IN CORDOBA, ARGENTINA. AN ASSESSMENT BASED ON SELF-REPORTED INFORMATION OF AGRICULTURAL APPLICATORS}

doi:10.1136/jech.2011.142976q.21

\begin{abstract}
${ }^{1} \mathrm{M}$ J Lantieri, ${ }^{2} \mathrm{R}$ A Fernández, ' $\mathrm{M}$ I Stimolo, ' $\mathrm{M}$ Butinof, ' $\mathrm{M}$ Blanco, ${ }^{1} \mathrm{M}$ Bonsignor, ${ }^{1}$ M Del Pilar Díaz. ${ }^{1}$ Universidad Nacional de Córdoba, Córdoba, Argentina; ${ }^{2}$ Universidad Católica de Córdoba, Córdoba, Argentina
\end{abstract}

Occupational pesticide exposure is a global health concern in agricultural settings. During the last 20 years, Argentina has experienced a process of "agriculturalization" characterised by a strong and continuous increase in the land area dedicated to crop growing. Cordoba, located in the center of the country, is one of the most important cropping province; its cultivated area increased from 3.397.050 ha in 1994/95 to 6.810 .500 ha in 2009/10. Moreover, an extensive agricultural model was set up based on the production with glyphosate-resistant transgenic soybean, no-till and intensive use of fertilisers and pesticides since 1996. In fact, a strong growth in the marketing of pesticides was observed: 155 million pounds in 1995 to 600 million pounds in 2007. Nevertheless, environmental impact and human health effects is poorly studied in this region. A population-based study of 880 agricultural applicators was carried out between 2007 and 2010. An exposure assessment was performed based on self-reported data. Workers completed a validated questionnaire describing several socio-demographic and lifestyle characteristics, pesticide and personal protective equipment use, lifetime exposure years and their health conditions. The main results indicate that our population is composed by young men (34.9 y, SD $11.04) ; 71 \%$ of them have mixed/applied pesticides up to 10 years and $46.5 \%$ live $<500 \mathrm{~m}$ with respect to the next sprayed crop. Furthermore, $67 \%$ do not use adequate PPE and 65\% apply on an average of $7000 \mathrm{ha}$ /year. Our research shows a risk scenario that warrants further evaluation particularly for chronic health effects occurrence.

\section{SP6-51 EFFECTS OF MATERNAL HISTORY OF ABUSE ON CHILD DEVELOPMENT AT AGE 3}

doi:10.1136/jech.2011.142976q.22

${ }^{1} \mathrm{C}$ Weller, ${ }^{*} \mathrm{~A}$ Metcalfe, ${ }^{2} \mathrm{~S} \mathrm{McD}$ onald, ${ }^{3} \mathrm{H}$ Kehler, ${ }^{2} \mathrm{~S}$ Tough. ${ }^{1}$ Department of Community Health Sciences, University of Calgary, Calgary, Alberta, Canada;
${ }^{2}$ Department of Paediatrics, University of Calgary, Calgary, Alberta, Canada; ${ }^{3} A l b e r t a$ Health Services, Calgary, Alberta, Canada

Introduction A community sample of pregnant women participated in a randomised controlled trial of prenatal care in Calgary, Alberta between 2001 and 2004. These women were followed-up when the child was 3 years old. Longitudinal data from these studies revealed that of children who were at high risk of developmental problems, $47 \%$ had mothers with a history of abuse. The primary objective was to test the hypothesis that maternal history of abuse was associated with child development at age three. Secondary objectives were (a) to examine this association according to type (physical, emotional, sexual, and financial abuse and neglect) and (b) to examine the prevalence of types of abuse.

Methods Questionnaire data from the initial study and the 3-year follow-up were used to determine the prevalence of the different types of abuse. Child development was measured using the Parents' Evaluation of Developmental Status instrument. $\chi^{2}$ analyses were performed to examine the relationship between these types of abuse and child development at age three.

Results Of the women who answered the questions regarding abuse, $34 \%$ reported a history of abuse. Of these women, $75 \%$ experienced emotional abuse, $49 \%$ experienced physical abuse, $42 \%$ experienced sexual abuse, $16 \%$ experienced neglect, and $14 \%$ experienced financial abuse. A statistically significant relationship was observed between physical abuse $(p=0.04)$, emotional abuse $(p=0.004)$ and risk of child development problems at age three.

Conclusion Maternal history of emotional and/or physical abuse potentially has a negative impact on child development at age three.

\section{SP6-52 TEACHING OF EPIDEMIOLOGY IN RUSSIA. HISTORY AND MODERNITY}

doi:10.1136/jech.2011.142976q.23

N Briko, T Sokolova, N Torchinsky. ${ }^{*}$ First Moscow State Medical University named after I.M. Sechenov, Moscow, Russia

Epidemiology for a long time was inseparable from clinical medicine. In the 18-19th centuries selected issues of epidemiology were taught in the departments of fundamental medicine, and therapeutic departments of the Russian Imperial Universities. Systematic teaching of epidemiology began in the late 19th century at Universities of St. Petersburg and Moscow. Teaching of epidemiology as a distinct discipline began in 1920 when the Medical Institute of Odessa opened one of the first in the world Department of Epidemiology. In the thirties in the Soviet Union were organised the Health and Sanitation departments, which were prepared epidemiologists and hygienists. Soviet epidemiology paid great attention to the epidemiology of infectious diseases. Within a short period there had been significant advances in the fight against smallpox, typhus, tuberculosis and malaria. In the last decade of 20th century began a new stage in the development of epidemiology in Russia. The basic principles of epidemiology as fundamental medical science were formulated, and it was reflected in the teaching of epidemiology in Medical Schools. In accordance with educational standards of 2011 important role devoted to the population-based approach on the study of infectious and non-communicable diseases, to the organisation of epidemiological studies and implementing evidence-based medicine. The cooperation between Russian Universities with Universities in Europe can be achieved real successes in teaching epidemiology in modern period. 